\title{
Type-2 Diabetes Mellitus Individuals Carry Different Periodontal Bacteria
}

\author{
Tamanna Ali1® ${ }^{\circledR}$, Adity Rumnaz ${ }^{1}$, Umme Laila Urmi ${ }^{1}$, Shamsun Nahar ${ }^{1}$,

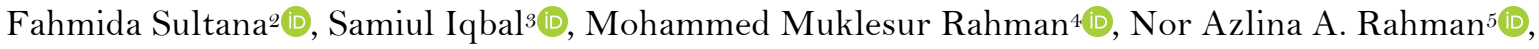 \\ Salequl Islam1무, Mainul Haque ${ }^{6}$ (1)
}

\begin{abstract}
'Department of Microbiology, Jahangirnagar University, Savar, Dhaka, Bangladesh.
${ }^{2}$ Department of Microbiology, Primeasia University, Dhaka, Bangladesh.

${ }^{3}$ Department of Orthodontics, Faculty of Dentistry, Dhaka, Bangladesh.

${ }^{4}$ Department of Orthodontics, Dhaka Dental College and Hospital, Mirpur, Dhaka, Bangladesh.

${ }^{5}$ Department of Physical Rehabilitation Sciences, Kulliyyah of Allied Health Sciences, International Islamic University Malaysia, Kuantan, Malaysia.

${ }^{6}$ Faculty of Medicine and Defence Health, National Defence University of Malaysia, Kuala Lumpur, Malaysia.
\end{abstract}

Correspondence: Md. Salequl Islam, Department of Microbiology, Jahangirnagar University, Savar, Dhaka, 1342, Bangladesh. E-mail: salequl@juniv.edu / Mainul Haque, Faculty of Medicine and Defence Health, Universiti Pertahanan, Nasional Malaysia, Kem Perdana Sungai Besi, Kuala Lumpur, Malaysia. E-mail: runurono@gmail.com

Academic Editor: Alidianne Fábia Cabral Cavalcanti

Received: 30 May 2020 / Review: 31 August 2020 / Accepted: 09 October 2020

How to cite: Ali T, Rumnaz A, Urmi UL, Nahar S, Rana M, Sultana F, Iqbal S, Rahman MM, Rahman NAA, Islam S, Haque M. Type-2 diabetes mellitus individuals carry different periodontal bacteria. Pesqui Bras Odontopediatria Clín Integr. 202 1; 21 :e0107. https://doi.org/10.1590/pboci.2021.049

\begin{abstract}
Objective: To identify etiologic microbiota associated periodontal diseases among diabetes patients and the factors related to the most commonly identified bacteria species. Material and Methods: Periodontal plaque samples from 11 diabetic participants and 13 non-diabetic controls were collected to assess their aerobic and anaerobic bacterial growth. Different distinct colonies were identified by microscopic and 16 srDNA sequencing. Pearson's chi-square tests were conducted to examine any association between categorical variables. Results: The diabetic subjects revealed a more intense plaque formation with a mean plaque index of 2.4 compared to 1.8 in non-diabetics. A total of 86 bacteria were isolated from 24 plaque samples, 44 were aerobic, and 42 were anaerobic. Only aerobic isolates, 22 from diabetic patients and 22 from non-diabetic patients, were evaluated in these analyses. Bacillus spp. (B. cereus mainly) and Klebsiella spp. (K. pneumoniae, K. aerogenes, $K$. oxytoca) were detected markedly higher in non-diabetic individuals than in diabetic subjects $(\mathrm{p}=0.026$ and $\mathrm{p}=0.021$, respectively). Some bacteria were only identified in the dental plaque of diabetic individuals, namely, Bacillus mojavensis, Enterobacter cloacae, Proteus mirabilis, Staphylococcus epidermidis, Staphylococcus hominis, Staphylococcus pasteuri, Streptococcus mutans, and Streptococcus pasteurianus. The presence of acid reflux and jaundice were significantly associated with the most common bacterial isolate, namely Bacillus spp., with the p-values of 0.007 and 0.001 , respectively. Conclusion: Type- 2 diabetes mellitus is associated with a higher amount of dental plaques. Periodontal plaque samples from diabetic and non-diabetic subjects possess differential microbial communities. Diabetic plaques contain more versatile microbes predominated by gram-positive streptococci and staphylococci.
\end{abstract}

Keywords: Oral Health; Periodontal Diseases; Periodontitis; Diabetes Mellitus, Type 2. 


\section{Introduction}

The oral cavity is the same lineage of the upper intestine, lower intestine, and rectum. Pathogens that remain in the oral cavity may transmit easily to other parts of the intestine and related organs. Varieties of microorganisms inhabit the oral cavity that provides a unique niche with the source of water and nutrients at a moderate temperature [1]. There are distinct microenvironments in the oral cavity, notably, on the hard and sticky surfaces on the teeth, in saliva fluid, and in subgingival to gingival crevicular fluid (GCF). The complex oral microbiota contains several hundred to thousand diverse species, as evidenced by both culture-based and culture-independent molecular approaches [2,3]. Microorganisms form multispecies communities on tooth surfaces in a matrix of extracellular polymeric substances. The oral microbial community in healthy humans is distinct from that of the disease-associated oral microbiota [4,5].

Most oral microorganisms are non-pathogenic, but opportunistic commensals keep oral health condition stable and protect against pathogenic microorganisms [6]. The alteration of typical oral bacterial species to pathogenic members results in dysbiosis and periodontal diseases (PD), such as periodontitis and gingivitis [7,8]. Periodontal diseases are customarily separated into infections affecting the underlying toothsupporting tissues of the periodontium, including the periodontal ligament, and the alveolar bone is known as periodontitis. PD is probably the most common chronic inflammatory disorder in adults and may lead to tooth loss in the absence of appropriate treatments. Infections particular to the gingival mucosa are known as gingivitis caused by a nonspecific inflammatory reaction in response to an increased mass of bacteria around the gingival crevice. Although oral diseases remain a significant public health burden worldwide with significant socio-economic impacts, yet these are frequently neglected in public health policy, particularly in developing countries [9]. Further, PD are closely interlinked to non-communicable diseases [10] such as pancreatic cancer [11], diabetes [12], atherosclerotic circulatory disease [13], osteoporosis, rheumatoid arthritis [14], pulmonary disorders [15], chronic renal disease, obesity and Alzheimer's disease [16,17]. Therefore, there has been a continuing interest in assessing the composition of the dental microbiota associated with health and disease.

The World Health Organization estimates 422 million adults in the world ( $8.5 \%$ of the population) had diabetes in 2014. The figure is expected to rise to 642 million people living with diabetes worldwide by 2040 [18]. Moreover, 75\% of people with diabetes live in low- and middle-income countries. The countries with the most people who have diabetes in upcoming years are predicted to be in Asian countries, including Bangladesh. The risk of periodontal diseases is increased by approximately threefold in diabetic subjects in comparison to non-diabetic individuals [19]. The diabetic status has been unequivocally reported as a significant risk factor for oral diseases [20,21]. Very few reports are available to elucidate PD of the Bangladeshi population [22,23]. To our knowledge, no study has reported yet about dental microbiota associated with type 2 diabetes mellitus (T2DM) humans. Understanding the importance, we have designed this current study-program to identify etiologic microbiota causing periodontal diseases among diabetes patients in Bangladesh.

\section{Material and Methods}

Sample Collection

Subjects who attended the Periodontology Department at Dhaka Dental College Hospital (DDCH), Mirpur, Bangladesh, for their dental treatment and care for periodontitis, were requested to be enrolled in this study. Participants underwent several periodontal examinations, namely, a periodontal probing, a radiographic 
analysis, community periodontal indexing, mobility charting, and an evaluation of the attached gingival amount. Eleven periodontal plaque samples (45.8\%) were analyzed from T2DM subjects, and the other 13 $(54.2 \%)$ from the non-diabetes group. Only supragingival plaque sampling was obtained. Three exact sites were chosen for selection per person: i) supra-gingival of the lower anterior segment (Lingual side) both sided central and lateral incisor area, ii) peri coronal area of a lower third molar tooth, iii) supragingival of upper premolar and molar (buccal side) area. The diabetic status of the participants is self-reported. However, the information was confirmed by cross-checking their medical records by a registered physician. Dental plaque samples were collected aseptically from only enrolled participants with the help of a dental doctor using paperpoints and swab sticks. Then, collected plaque samples were submerged into prelabeled cryovials containing $400 \mu$ l PBS (Phosphate buffer saline), stored in an icebox, and a strict cold chain was maintained to transport the samples to the microbiology laboratory within three hours of collection.

Bacteria Isolation and Presumptive Identification

Plaque samples were mixed well by vortex and inoculated into sugar supplemented-Brain Heart Infusion Agar (BHIA) with and without Congo Red in parallel. Inoculated cultures on BHIA were incubated at $37{ }^{\circ} \mathrm{C}$ for 24-hour under aerobic conditions. BHIA-incubation samples were incubated for 48-hour under anaerobic conditions. Only aerobic isolates were included in this analysis. Each of the bacteria was subjected to Gram's reaction, catalase test, and conventional biochemical test for presumptive identification.

Molecular Identification of the Dental Isolates

$16 \mathrm{~S}$ rDNA analyses confirmed the identification of isolated bacteria. For the preparation of template DNA, the NucleoSpin tissue kit was used following the manufacturer's instruction (Macherey-Nagel, Germany). The DNA templates were subjected to a polymerase chain reaction (PCR) using $16 \mathrm{~S}$ rDNA primer pair 16sUni-F: AGAGTTTGATCCTGGCTCAG and 16sUni-R: TACGGTTACCTTGTTACGACTT, as described elsewhere [24]. In brief, prepared bacterial DNA (1.0 $\mu \mathrm{L})$ was added to a $2 \mathrm{X}$ PCR pre-mixture, $(12$ $\mu \mathrm{L}$, GEneON GMBH, Ludwigshafen am Rhein, Germany) and five pmol of each primer ( $1 \mu \mathrm{L})$, and deionized water remaining to a final volume of $24 \mu \mathrm{L}$. Reactions underwent an initial denaturation at $94{ }^{\circ} \mathrm{C}$ for five minutes followed by 32 cycles of amplification (2720 Thermal Cycler; Applied Biosystem, Thermo Fisher Scientific, Waltham, MA, USA), consisting of denaturation 30 s at $94{ }^{\circ} \mathrm{C}$, annealing 30 s at $56{ }^{\circ} \mathrm{C}$, extension $1-$ min at $72{ }^{\circ} \mathrm{C}$, and a final 7 -min extension at $72{ }^{\circ} \mathrm{C}$. Amplicons (1466 bp DNA) were visualized under UV light after $1.2 \%$ agarose gel electrophoresis followed by staining with ethidium bromide. The amplified products were purified with a QIAquick PCR purification kit (Qiagen, Hilden, Germany) according to manufacturer instruction. The purified DNA was stored at $-20{ }^{\circ} \mathrm{C}$ and sequenced subsequently and blasted with an online database (https://blast.ncbi.nlm.nih.gov) to confirm the identity of the isolates. Capillary Electrophoresis Sequencing (CES) was obtained from a commercial service provider (Macrogen Inc, Seul, South Korea).

\section{Statistical Analysis}

A validated Bengali version of the questionnaire was used for data collection. Verified data were entered and subsequently analyzed using IBM SPSS statistics data editor (version 21). Descriptive statistics were used to describe the categorical socio-demographic variables. Pearson's chi-square and Fisher's Exact tests were conducted to examine the association between bacterial species from the isolates and diabetic status. The level of significance was set at $5 \%$. 


\section{Ethical Statement}

This study was approved by the Ethics and Research Review Committee of the Jahangirnagar University Faculty of Biological Sciences [No. BBEC, JU/M 2017 12(4) dated 27.12.2017]. Informed written consent was obtained from each study participant before collecting their data and biospecimens.

\section{Results}

A total of 24 patients who attended Dhaka Dental College Hospital were enrolled in the study. The diabetic subjects showed a more intense plaque formation in comparison with non-diabetic individuals, where their average plaque indexes were 2.4 and 1.8, respectively. Plaque index was made by observing the amount of plaque accumulation in the gingival sulcus or pocket area. Overall female participants were two-third (16/24) in the study. The age of the study-subjects was from 11 to 70 years-old. Most of the diabetic patients were found in the 41-50- and 51-60-years age groups.

A total of 86 bacteria were isolated from 24 dental plaque samples. Of them, 44 bacteria were isolated from the aerobic condition and 42 from the anaerobic condition. Only the aerobic isolates, 22 from diabetic patients and 22 from non-diabetic participants, were analyzed. The colony characteristics of different five types of isolates on TSA agar medium were white, off-white, with a rough edge, transparent, and slimy. Therefore, identifying dental bacteria by observing colony colors on TSA may be presumptive but challenging to conclude. Gram's staining was conducted, followed by molecular-based identification by $16 \mathrm{~S}$ rDNA sequencing. Obtained sequences were compared to the online database of NCBI basic local alignment search tool (BLAST).

The study identified several genera bacteria recovered from periodontal sites, namely, Bacillus spp., Escherichia spp., Enterobacter spp., Staphylococcus spp., Streptococcus spp. in both diabetic and non-diabetic participants. At species-level analysis, some bacteria were detected both in diabetic and non-diabetic, namely, Bacillus cereus, Bacillus licheniformis, Escherichia coli, Staphylococcus warneri, and Streptococcus saliverius. Of these, E. coli was found a higher frequency in diabetic subjects and B. cereus in the non-diabetic group. In contrast, some identified bacterial species were distinct from individuals with diabetes and those without. The bacterial species only found in dental plaque of diabetic individuals were Bacillus mojavensis, Enterobacter cloacae, Proteus mirabilis, Staphylococcus epidermidis, Staphylococcus hominis, Staphylococcus pasteuri, Streptococcus mutans, and Streptococcus pasteurianus. On the other hand, the bacteria found only in non-diabetic subjects were Bacillus subtilis, Klebsiella aerogenes, K. oxytoca, K. pneumoniae, Enterobacter ludwigii, and Staphylococcus aureus.

Further statistical analysis showed a significant association between diabetic status with Bacillus spp. $(\mathrm{p}=0.026)$ and Klebsiella spp. $(\mathrm{p}=0.021)$, indicating the two bacterial species were more common in non-diabetics than diabetic patients. No significant association was found between diabetic status with either Enterobacter spp., E. coli, Staphylococcus spp., Streptococcus spp. or Proteus spp. (Table 1).

Table 1. Comparing bacterial species in isolates from diabetics vs. non-diabetics.

\begin{tabular}{cccc}
\hline Bacterial Isolates & $\begin{array}{c}\text { Diabetics } \\
\mathrm{N}(\%)\end{array}$ & $\begin{array}{c}\text { Non-Diabetics } \\
\mathrm{N}(\%)\end{array}$ & p-value \\
\hline $\begin{array}{c}\text { Bacillus } \boldsymbol{s} p \boldsymbol{p} \text {. } \\
\text { Yes }\end{array}$ & $4(18.2)$ & $11(50.0)$ & $0.026^{*}$ \\
No & $18(81.8)$ & $11(50.0)$ & \\
Klebsiella $s p p$. & & & \\
Yes & $0(0.0)$ & $6(27.3)$ & $0.012^{* *}$ \\
No & $22(100)$ & $16(72.7)$ &
\end{tabular}




$\begin{array}{lccc}\text { Enterobacter spp. } & & \\ \text { Yes } & 3(13.6) & 1(4.5) & 0.607^{* *} \\ \text { No } & 19(86.4) & 21(95.5) & \\ \begin{array}{l}\text { E. coli } \\ \text { Yes }\end{array} & 4(18.2) & 1(4.5) & 0.345^{* *} \\ \text { No } & 18(81.8) & 21(95.5) & \\ \text { Staphylococcus spp. } & 5(22.7) & 2(9.1) & 0.412^{* *} \\ \text { Yes } & 17(77.3) & 20(90.9) & \\ \text { No } & 5(22.7) & 1(4.5) & 0.185^{* *} \\ \text { Streptococcus spp. } & 17(77.3) & 21(95.5) & \\ \text { Yes } & 1(4.5) & 0(0.0) & 1.000^{* * *} \\ \text { No } & 21(95.5) & 22(100.0) & \\ \text { Proteus spp. } & \end{array}$

*Pearson chi-square test; **Fisher's Exact test.

The previous finding indicated that the most common bacterial isolated was Bacillus spp.; hence it seems essential to find out the factors associated with these isolates (Table 2). Besides the significantly higher Bacillus spp. isolates among non-diabetics compared to people with diabetes (Table 1). It was found that the presence of acid reflux $(\mathrm{p}=0.007)$ and jaundice $(\mathrm{p}=0.001)$ were also significantly associated with positive Bacillus spp. Isolates.

Table 2. Factors associated with Bacillus $s p p$. in bacterial isolates from periodontal sites.

\begin{tabular}{|c|c|c|c|}
\hline \multirow{2}{*}{ Factors } & \multicolumn{2}{|c|}{ Bacillus spp. isolates } & \multirow[b]{2}{*}{ p-value } \\
\hline & $\begin{array}{c}\text { Positive } \\
\mathrm{N}(\%)\end{array}$ & $\begin{array}{c}\text { Negative } \\
\mathrm{N}(\%)\end{array}$ & \\
\hline \multicolumn{4}{|l|}{ Age (in Years) } \\
\hline$\leq 50$ & $13(86.7)$ & $18(62.1)$ & $0.162^{* *}$ \\
\hline$>50$ & $2(13.3)$ & $11(37.9)$ & \\
\hline \multicolumn{4}{|l|}{ Gender } \\
\hline Male & $7(46.7)$ & $7(24.1)$ & $0.177^{* *}$ \\
\hline Female & $8(53.3)$ & $22(75.9)$ & \\
\hline \multicolumn{4}{|l|}{ Education } \\
\hline Literate & $11(84.6)$ & $15(65.2)$ & $0.270^{* *}$ \\
\hline Illiterate & $2(15.4)$ & $8(34.8)$ & \\
\hline \multicolumn{4}{|l|}{ Marital Status } \\
\hline Married & $11(73.3)$ & $26(89.7)$ & $0.207 * *$ \\
\hline Single & $4(26.7)$ & $3(10.3)$ & \\
\hline \multicolumn{4}{|l|}{ Blood Pressure } \\
\hline Yes & $2(15.4)$ & $5(21.7)$ & $1.000^{* *}$ \\
\hline No & $11(84.6)$ & $18(78.3)$ & \\
\hline \multicolumn{4}{|l|}{ Acid Reflux } \\
\hline Yes & $10(76.9)$ & $7(30.4)$ & $0.007 *$ \\
\hline No & $3(23.1)$ & $16(69.6)$ & \\
\hline \multicolumn{4}{|l|}{ Jaundice } \\
\hline Yes & $7(53.8)$ & $1(4.3)$ & $0.001 *$ \\
\hline No & $6(46.2)$ & $22(95.7)$ & \\
\hline \multicolumn{4}{|l|}{ Smoking } \\
\hline Yes & $2(15.4)$ & $1(4.3)$ & $0.539^{* *}$ \\
\hline No & $11(84.6)$ & $22(95.7)$ & \\
\hline
\end{tabular}

*Pearson chi-square test; **Fisher's Exact test.

\section{Discussion}

This study investigated the aerobic microbiological composition from dental plaques in human subjects with and without T2DM. The most frequently isolated bacteria from the gum specimens were Bacillus 
cereus, Escherichia coli, Streptococcus salivarius, Klebsiella pneumonia, Staphylococcus warneri, and Enterobacteria cloacae. Plaque samples of diabetic subjects showed a higher percentage of gram-positive Streptococci and Staphylococci than in non-diabetic samples. Succinctly, Bacillus cereus and Klebsiella pneumonia were found noticeably higher in non-diabetic plaque samples. Taken together, identified dental microbiota from diabetic humans varied substantially than that of non-diabetic subjects. Such different microbial composition may result from the effect of diabetes in altering the local environment within the periodontal pocket that favored the growth of certain bacterial species. The altered microbial homeostasis in a system leads to an inconsistent and compromised immune system [25,26]. Likely, some other studies have identified the association of altered gut microbiota (dysbiosis) with varieties of autoimmune disorders, namely, T2DM and inflammatory bowel disease (IBD) [27]. However, research in dental or oral microbiology remains in its infancy, and dysbiosis roles of dental microbiota to other systemic diseases have not been elucidated well. The effects of more diversified oral microbiota in diabetic subjects are not yet apparent but probably relate to increased local or systemic inflammation. Hence, more severe periodontitis exhibited in diabetic individuals of this study were supported by earlier reports $[19,28]$.

Identifying the high frequency of Bacillus cereus in the non-diabetic dental-plaque in this study showed agreement with other research findings that states its etiologic association to periodontal disease [29,30]. B. cereus has also been associated with different types of food-borne illnesses [31]. The pathogen can withstand a long time in contaminated foods because of their resistant endospores and easily transmitted to dental plaque. The endospore-forming property of the B. cereus may help it surviving a long time in the dental plaque ecosystem. However, it is still unclear why this bacterium presents more frequently in the plaques of nondiabetic individuals. Like B. cereus, three three Klebsiella species, namely, K. pneumoniae, K. oxytoca, and K. aerogenes, were only exclusively detected in non-diabetic plaque samples. Klebsiella pneumoniae is an encapsulated oropharyngeal flora that causes mainly pneumonia and urinary tract infection. The bacteria are found reasonably in sputum and periodontitis [32,33]. The hypermucoviscosity property of the pathogen allows conveniently to attach on teeth surfaces. Klebsiella spp. and other Enterobacteriaceae produce volatile sulfides and cadaverine that are related to oral mal-odor compounds [34]. The oral cavity may serve as a reservoir for these pathogens for subsequent infection into the lung and intestine. These respiratory and gastrointestinal pathogens may transmit and colonize the oropharyngeal region from poor oral hygiene practice or untreated periodontal diseases. However, Klebsiella spp. and B. cereus were reported more in uncomplicated periodontitis [35], as attested by this study.

More versatile microorganisms were identified in the dental plaque samples of diabetic subjects. The predominant bacteria were different species of Staphylococcus and Streptococcus. The microbial diversification of oral communities indicates some degree of disruption of the normal oral flora. The microbial dysbiosis provides a bidirectional link to systemic diseases like diabetes and periodontal tissue destruction [36,37]. Hence, the dysbiotic community can drive periodontitis and diabetes as risk factors for each other [28,38]. Streptococci and Staphylococci both secrets various pathogenic factors like extracellular polymeric substances, toxins, and enzymes that induce various systemic diseases, such as infective endocarditis, purulent infections, rheumatoid arthritis, brain hemorrhage, intestinal inflammation, and autoimmune diseases [37,39].

Further, streptococcal M protein, lipoteichoic acid, and hyaluronic acid capsule assist the bacteria in attaching in dental plaque and exhibiting virulence. A remarkable adhesion molecule, fibronectin-binding proteins of staphylococci, and streptococci were reported for the bacterial attachment to dental pellicle and subsequent plaque formation [40-42]. The studies also showed a higher amount of plaque formation was 
positively correlated with increased periodontitis [43]. Increased plaque formation in T2DM subjects in this study may be affected by their metabolic defects that contribute to high glucose levels and subsequent higher microbial growth in the microenvironment. Hyperglucagonemia, a state of elevated glucagon hormone in T2DM, assist higher bacterial infection [44]. Hence, the metabolic stress of diabetic state and associated infections aggravates the health situation. Therefore, plaque management, either by lifestyle intervention, treatment, or diabetic control, could be the vehicle to reduce the local periodontal tissue destruction and systemic inflammation.

This study also found a significant association between the presence of acid reflux and jaundice with positive Bacillus spp. isolates in dental plaques. Even though Bacillus spp. prebiotics in the gut was said to be able to prevent acid reflux [45], but the mechanism might not be the same with the presence of the bacteria in dental plaque. On the other hand, acid reflux from the stomach, such as in gastroesophageal reflux disease (GERD), can enter the mouth and demineralize the patient's teeth, causing dry mouth subsequently can intensify dental bacteria and plaque formation [46].

Furthermore, even though this study found jaundice was significantly associated with positive Bacillus spp. isolates in dental plaques, an experimental study was done in India found that probiotic Bacillus Clausii given to late preterm and term newborn babies reduced the need for phototherapy for neonatal jaundice and also reduced the duration of phototherapy of these babies compared to the control group [47]. Again, it could be due to the different mechanisms acting in the other parts of the body.

This study does have some significant limitations. Streptococcus mutans is a commonly found bacteria in the human oral cavity. However, we detected the bacteria only in the dental plaque samples of diabetic subjects but not in non-diabetic specimens. These could be because of some methodological flaws. Detail risk behavior data of the study participants were not collected and analyzed. Some more potential factors that could influence the differential microbial composition, namely, host response, oral hygiene habits, oral health care access, were not included in the study. This study was a cross-sectional analysis, and followed up was not done because of resource limitation. The convenient sampling was undertaken in a government dental hospital in Bangladesh. Therefore, patients in this study were from lower to middle-income class families who seek cheaper and subsidized treatment from national-funded hospitals. This study had analyzed only a few dental plaque samples for fund constraint reasons. The small sample size was a constraint to performing fully powered statistical analyses. Further, we reported only a part of aerobic bacteria from dental plaque samples. Separate bacterial cultivation under reduced oxygen conditions in the candle jar produced similar microorganisms confirmed by $16 \mathrm{~s}$ rDNA analysis. We could not provide ideal anaerobic culture or microbiome analyses because of our confined resources. However, our results were generated from a resource-limited setting and maintained internal validity by repeated independent experiments where necessary. This study's results could be a practical and doable scheme for low-income countries, including Bangladesh. The findings had shed some light on several aerobic pathogens isolated from periodontal sites in patients with T2DM and without. Further studies may be required to determine the external validity of our findings.

\section{Conclusion}

T2DM is associated with a higher amount of dental plaques. Periodontal plaque samples from diabetic and non-diabetic subjects possess differential microbial communities. Diabetic plaques contain more versatile microbes predominated by gram-positive streptococci and staphylococci. Improved understanding of microbial etiology for periodontitis in T2DM will guide for appropriate therapeutics. 


\section{Authors' Contributions}

\begin{tabular}{|c|c|c|}
\hline TA & (D) https://orcid.org/0000-0001-9139-6095 & $\begin{array}{l}\text { Conceptualization, Methodology, Formal Analysis, Investigation, Writing - Original Draft and } \\
\text { Writing - Review and Editing. }\end{array}$ \\
\hline AR & (D) https://orcid.org/0000-0001-5137-9944 & Conceptualization, Methodology, Formal Analysis, Investigation, Writing - Original Draft. \\
\hline ULU & (iD) https://orcid.org/0000-0003-1327-1638 & Conceptualization, Methodology, Formal Analysis, Investigation, Writing - Original Draft. \\
\hline SN & (iD) https://orcid.org/0000-0002-3580-5576 & Conceptualization, Methodology, Formal Analysis, Investigation, Writing - Original Draft. \\
\hline MR & (iD) https://orcid.org/0000-0002-3256-0235 & Conceptualization, Methodology, Formal Analysis, Investigation, Writing - Original Draft. \\
\hline FS & (iD) https://orcid.org/0000-0003-3278-165X & Conceptualization, Methodology, Formal Analysis, Investigation, Writing - Original Draft. \\
\hline SI & (iD) https://orcid.org/0000-0003-1625-5924 & Conceptualization, Methodology, Formal Analysis, Investigation, Writing - Original Draft. \\
\hline MMR & (iD) https://orcid.org/0000-0001-6389-5380 & Conceptualization, Methodology, Formal Analysis, Investigation, Writing - Original Draft. \\
\hline NAAR & (iD) https://orcid.org/0000-0002-9046-6183 & Conceptualization, Methodology, Formal Analysis, Investigation, Writing - Original Draft. \\
\hline & (iD) https://orcid.org/0000-0001-6131-4132 & Conceptualization, Methodology, Formal Analysis, Investigation, Writing - Original Draft. \\
\hline MH & (iD) https://orcid.org/0000-0002-6124-7993 & $\begin{array}{l}\text { Conceptualization, Methodology, Formal Analysis, Investigation, Writing - Original Draft and } \\
\text { Writing - Review and Editing. }\end{array}$ \\
\hline
\end{tabular}

\section{Financial Support}

This work was partially supported by a research grant from Jahangirnagar University and Bangladesh Medical Research Council awarded to Dr. Salequl Islam [BMRC/Grants/2017-2018/398(1-72)].

\section{Conflict of Interest}

The authors declare no conflicts of interest.

\section{Data Availability}

The data used to support the findings of this study can be made available upon request to the corresponding author.

\section{Acknowledgments}

The authors would like to thank the study participants for their active support.

\section{References}

[1] Griffen AL, Beall CJ, Campbell JH, Firestone ND, Kumar PS, Yang ZK, et al. Distinct and complex bacterial profiles in human periodontitis and health revealed by $16 \mathrm{~S}$ pyrosequencing. ISME $\mathrm{J}$ 2012; 6(6):1176-85. https://doi.org/10.1038/ismej.2011.191

[2] Dewhirst FE, Chen T, Izard J, Paster BJ, Tanner AC, Yu WH, et al. The human oral microbiome. J Bacteriol 2010; 192(19):5002-17. https://doi.org/10.1128/JB.00542-10

[3] Arweiler NB, Netuschil L. The Oral Microbiota. Adv Exp Med Biol 2016; 902:45-60. https://doi.org/10.1007/978-3-319-31248-4_4

[4] Dabdoub SM, Ganesan SM, Kumar PS. Comparative metagenomics reveals taxonomically idiosyncratic yet functionally congruent communities in periodontitis. Sci Rep 2016; 6:38993. https://doi.org/10.1038/srep38993

[5] Lamont RJ, Koo H, Hajishengallis G. The oral microbiota: dynamic communities and host interactions. Nat Rev Microbiol 2018; 16(12):745-59. https://doi.org/10.1038/s41579-018-0089-x

[6] Zbinden A, Bostanci N, Belibasakis GN. The novel species Streptococcus tigurinus and its association with oral infection. Virulence 2015; 6(3):177-82. https://doi.org/10.4161/21505594.2014.970472

[7] Hajishengallis G, Liang S, Payne MA, Hashim A, Jotwani R, Eskan MA, et al. Low-abundance biofilm species orchestrates inflammatory periodontal disease through the commensal microbiota and complement. Cell Host Microbe 2011; 10(5):497-506. https://doi.org/10.1016/j.chom.2011.10.006

[8] Darveau RP, Hajishengallis G, Curtis MA. Porphyromonas gingivalis as a potential community activist for disease. J Dent Res 2012; 91(9):816-20. https://doi.org/10.1177/0022034512453589

[9] Beaglehole R. Sugar-sweetened beverages, obesity, diabetes, and oral health: a preventable crisis. Pacific Health Dialog 2014; 20(1):39-42.

[10] Jin LJ, Lamster IB, Greenspan JS, Pitts NB, Scully C, Warnakulasuriya S. Global burden of oral diseases: emerging concepts, management, and interplay with systemic health. Oral Dis 2016; 22(7):609-19. https://doi.org/10.1111/odi.12428

[11] Jacob JA. Study links periodontal disease bacteria to pancreatic cancer risk. JAMA 2016; 315(24):2653-4. https://doi.org/10.1001/jama.2016.6295

[12] Casarin RC, Barbagallo A, Meulman T, Santos VR, Sallum EA, Nociti FH, et al. Subgingival biodiversity in subjects with uncontrolled type-2 diabetes and chronic periodontitis. J Periodontal Res 2013; 48(1):30-6. https://doi.org/10.1111/j.1600-0765.2012.01498.x 
[13] Nguyen CM, Kim JW, Quan VH, Nguyen BH, Tran SD. Periodontal associations in cardiovascular diseases: The latest evidence and understanding. J Oral Biol Craniofac Res 2015; 5(3):203-6. https://doi.org/10.1016/j.jobcr.2015.06.008

[14] Hendler A, Mulli TK, Hughes FJ, Perrett D, Bombardieri M, Houri-Haddad Y, et al. Involvement of autoimmunity in the pathogenesis of aggressive periodontitis. J Dent Res 2010; 89(12):1389-94. https://doi.org/10.1177/0022034510381903

[15] Linden GJ, Lyons A, Scannapieco FA. Periodontal systemic associations: a review of the evidence. J Clin Periodontol 2013; 4O(Suppl 14): S8-S19. https://doi.org/10.1111/jcpe.12064

[16] Poole S, Singhrao SK, Kesavalu L, Curtis MA, Crean S. Determining the presence of periodontopathic virulence factors in short-term postmortem Alzheimer's disease brain tissue. J Alzheimers Dis 2013; 36(4):665-77. https://doi.org/10.3233/JAD-121918

[17] Kumar PS. From focal sepsis to periodontal medicine: A century of exploring the role of the oral microbiome in systemic disease. J Physiol 2016; 595(2):465-76. https://doi.org/10.1113/JP272427

[18] Kocher T, Konig J, Borgnakke WS, Pink C, Meisel P. Periodontal complications of hyperglycemia/diabetes mellitus: Epidemiologic complexity and clinical challenge. Periodontol 2000 2018; 78(1):59-97. https://doi.org/10.1111/prd.12235

[19] Mealey BL, Ocampo GL. Diabetes mellitus and periodontal disease. Periodontol 2000 2007; 44(1):127-53. https://doi.org/10.1111/j.1600-0757.2006.00193.x

[20] Chavarry NG, Vettore MV, Sansone C, Sheiham A. The relationship between diabetes mellitus and destructive periodontal disease: a meta-analysis. Oral Health Prev Dent 2009; 7(2):107-27.

[21] Khader YS, Dauod AS, El-Qaderi SS, Alkafajei A, Batayha WQ. Periodontal status of diabetics compared with nondiabetics: a meta-analysis. J Diabetes Complications 2006; 20(1):59-68. https://doi.org/10.1016/j.jdiacomp.2005.05.006

[22] Akhter R, Hassan NM, Aida J, Zaman KU, Morita M. Risk indicators for tooth loss due to caries and periodontal disease in recipients of free dental treatment in an adult population in Bangladesh. Oral Health Prev Dent 2008; 6(3):199-207.

[23] Arvidson-Bufano UB, Holm AK. Dental health in urban and rural areas of central and western Bangladesh. Odontostomatol Trop 1990; 13(3):81-6.

[24] Srinivasan R, Karaoz U, Volegova M, MacKichan J, Kato-Maeda M, Miller S, et al. Use of 16S rRNA gene for identification of a broad range of clinically relevant bacterial pathogens. PloS one 2015; 10(2):e0117617. https://doi.org/10.1371/journal.pone.0117617

[25] Belkaid Y, Harrison OJ. Homeostatic immunity and the microbiota. Immunity 2017; 46(4):562-76. https://doi.org/10.1016/j.immuni.2017.04.008

[26] Macpherson AJ, Harris NL. Interactions between commensal intestinal bacteria and the immune system. Nat Rev Immunol 2004; 4(6):478-85. https://doi.org/10.1038/nri1373

[27] Alvarez-Mercado AI, Navarro-Oliveros M, Robles-Sanchez C, Plaza-Diaz J, Saez-Lara MJ, Munoz-Quezada S, et al. Microbial population changes and their relationship with human health and disease. Microorganisms 2019; 7(3):68. https://doi.org/10.3390/microorganisms7030068

[28] Preshaw PM, Alba AL, Herrera D, Jepsen S, Konstantinidis A, Makrilakis K, et al. Periodontitis and diabetes: a twoway relationship. Diabetologia 2012; 55(1):21-31. https://doi.org/10.1007/s00125-011-2342-y

[29] Schuch R, Pelzek AJ, Fazzini MM, Nelson DC, Fischetti VA. Complete genome sequence of Bacillus cereus Sensu Lato Bacteriophage Bcp1. Genome Announc 2014; 2(3):e00334-14. https://doi.org/10.1128/genomeA.00334-14

[30] Helgason E, Caugant DA, Olsen I, Kolsto AB. Genetic structure of population of Bacillus cereus and B. thuringiensis isolates associated with periodontitis and other human infections. J Clin Microbiol 2000; 38(4):1615-22. https://doi.org/10.1 128/JCM.38.4.1615-1622.2000

[31] Tewari A, Abdullah S. Bacillus cereus food poisoning: international and Indian perspective. J Food Sci Technol 2015; 52(5):2500-11. https://doi.org/10.1007/s13197-014-1344-4

[32] Ikeda M, Mizoguchi M, Oshida Y, Tatsuno K, Saito R, Okazaki M, et al. Clinical and microbiological characteristics and occurrence of Klebsiella pneumoniae infection in Japan. Int J Gen Med 2018; 11:293-9. https://doi.org/10.2147/IJGM.S166940

[33] Scannapieco FA, Mylotte JM. Relationships between periodontal disease and bacterial pneumonia. J Periodontol 1996; 67(10 Suppl):1114-22. https://doi.org/10.1902/jop.1996.67.10s.1114

[34] Goldberg S, Cardash H, Browning H 3rd, Sahly H, Rosenberg M. Isolation of Enterobacteriaceae from the mouth and potential association with malodor. J Dent Res 1997; 76(11):1770-5. https://doi.org/10.1177/00220345970760110801

[35] Souto R, Andrade AFB, Uzeda M, Colombo APV. Prevalence of "non-oral" pathogenic bacteria in subgingival biofilm of subjects with chronic periodontitis. Braz J Microbiol 2006; 37(3):208-15. https://doi.org/10.1590/S1517-83822006000300002

[36] Bui FQ, Almeida-da-Silva CLC, Huynh B, Trinh A, Liu J, Woodward J, et al. Association between periodontal pathogens and systemic disease. Biomed J 2019; 42(1):27-35. https://doi.org/10.1016/j.bj.2018.12.001 
[37] Correa JD, Fernandes GR, Calderaro DC, Mendonca SMS, Silva JM, Albiero ML, et al. Oral microbial dysbiosis linked to worsened periodontal condition in rheumatoid arthritis patients. Sci Rep 2019; 9(1):8379. https://doi.org/10.1038/s41598-019-44674-6

[38] Wu YY, Xiao E, Graves DT. Diabetes mellitus related bone metabolism and periodontal disease. Int J Oral Sci 2015; 7(2):63-72. https://doi.org/10.1038/ijos.2015.2

[39] Roberts FA, Darveau RP. Microbial protection and virulence in periodontal tissue as a function of polymicrobial communities: symbiosis and dysbiosis. Periodontol 2000 2015; 69(1):18-27. https://doi.org/10.1111/prd.12087

[40] Rocha CL, Fischetti VA. Identification and characterization of a novel fibronectin-binding protein on the surface of group A streptococci. Infect Immun 1999; 67(6):2720-8. https://doi.org/10.1128/IAI.67.6.2720-2728.1999

[41] Rudiger SG, Carlen A, Meurman JH, Kari K, Olsson J. Dental biofilms at healthy and inflamed gingival margins. J Clin Periodontol 2002; 29(6):524-30. https://doi.org/10.1034/j.1600-051x.2002.290609.x

[42] Foster TJ. The remarkably multifunctional fibronectin-binding proteins of Staphylococcus aureus. Eur J Clin Microbiol Infect Dis 2016; 35(12):1923-31. https://doi.org/10.1007/s10096-016-2763-0

[43] Monteiro MF, Casati MZ, Taiete T, Vale HF, Nociti FH Jr, Sallum EA, et al. Periodontal clinical and microbiological characteristics in healthy versus generalized aggressive periodontitis families. J Clin Periodontol 2015; 42(10):914-21. https://doi.org/10.1111/jcpe.12459

[44] Rocha DM, Santeusanio F, Faloona GR, Unger RH. Abnormal pancreatic alpha-cell function in bacterial infections. N Engl J Med 1973; 288(14):700-3. https://doi.org/10.1056/NEJM197304052881402

[45] Schmidt E. Benefits of taking Bacillus species probiotics. Meridian Health Clinic. 2015. Available from: https://meridianhealthclinic.com/benefits-of-taking-a-probiotic-especially-bacillus-species/. [Accessed on April 10, 2020].

[46] Jacobs JE. Can GERD cause tooth decay? Everyday Health. 2007. Available from: https://www.everydayhealth.com/dental-health/oral-conditions/specialist/jacobs/can-gerd-cause-tooth-decay.aspx. [Accessed on April 10, 2020].

[47] Chandrasekhar J, Varghese TP, Gopi A, Raj M, Sudevan R, Jayakumar H. Treatment effect of probiotic Bacillus Clausii on neonatal jaundice in late preterm and term newborn babies: an experimental study. Pediatr Ther 2017; 7(3):326-31. https://doi.org/10.4172/2161-0665.1000326 